\title{
Micelle Formation inside Zeolites: A Critical Step in Zeolite Surfactant-Templating Observed by Raman Microspectroscopy
}

\author{
Guillaume Fleury, Monica J. Mendoza-Castro, Noemi Linares, Maarten B. J. Roeffaers,* \\ and Javier García-Martínez*
}

Cite This: ACS Materials Lett. 2022, 4, 49-54

Read Online

\section{ACCESS |}

山ll Metrics \& More

Article Recommendations

Supporting Information

ABSTRACT: Micelle formation inside faujasite (FAU) zeolite, a critical step in the introduction of mesoporosity in zeolites by surfactant templating, has been confirmed by both ${ }^{13} \mathrm{C} N M R$ and Raman spectroscopy. Here we provide unambiguous evidence of the incorporation of surfactant molecules inside zeolites during the first step of the surfactant-templating process followed by their selfassembly into micelles after hydrothermal treatment. The homogeneous presence of these micelles throughout zeolite crystals has been directly observed by Raman microspectroscopy, confirming the uniform incorporation of mesoporosity in zeolites by surfactant templating.

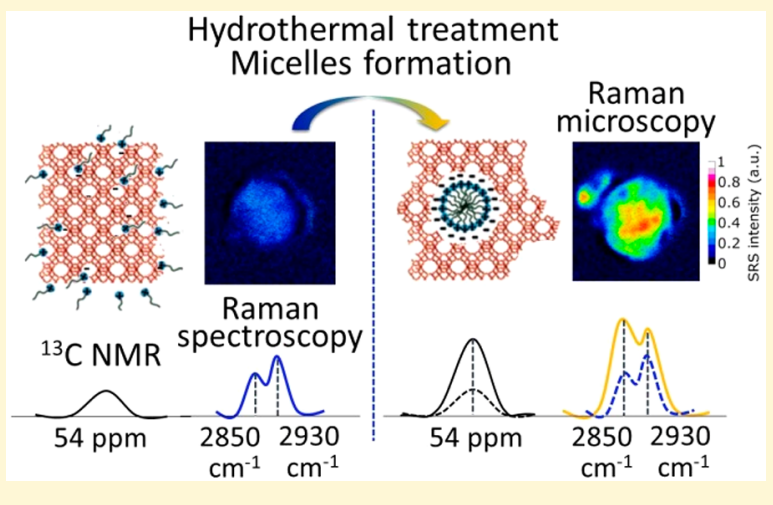

7 he development of new synthetic approaches to overcome the diffusion limitations of zeolites has been the focus of numerous studies in the past decade. $^{1-3}$ The incorporation of a secondary mesoporous system in zeolites is a successful method for overcoming the drawbacks related to their limited accessibility, greatly enhancing their performance in the transformation of bulky molecules. ${ }^{4-6}$ Among the various current methods available to impart secondary porosity in zeolites, ${ }^{2,3,7,8}$ the postsynthetic treatment of zeolites with cationic surfactants is particularly suitable because it maintains the key features of the original zeolite such as the crystallinity, strong acidity, and hydrothermal stability. $1,9,10$

This method, known as surfactant templating, proceeds through the different steps summarized in the scheme shown in Figure 1A. First, the partial cleavage of $\mathrm{Si}-\mathrm{O}-\mathrm{Si}$ bonds by the action of a base generates negatively charged $\mathrm{Si}-\mathrm{O}^{-}$ species in the zeolite framework. In a second step, the individual $\mathrm{CTA}^{+}$molecules are attracted to the interior of the zeolite by the aforementioned $\mathrm{SiO}^{-}$species. Finally, when the local concentration of $\mathrm{CTA}^{+}$inside the zeolite is sufficiently high, micelles are formed. This causes the rearrangement of the zeolite structure to accommodate the micelles, introducing mesoporosity, ${ }^{11}$ which causes the expansion of the crystal. ${ }^{12}$ The details of this process are still elusive, but a number of techniques have been used to gain insights into the key aspects of this transformation, including its kinetics and thermody- namics, which show that surfactant templating is not only thermodynamically favorable but also kinetically accessible. ${ }^{11,13}$ However, one of the key steps in the surfactant templating of zeolites, namely, the formation of micelles that cause the crystal rearrangement that leads to the formation of mesopores, has never been directly confirmed. So far, only indirect evidence of micelle formation inside zeolites has been found. Thermogravimetric analysis has been used to determine the amount of $\mathrm{CTA}^{+}$interacting with the crystalline structure, and small-angle $\mathrm{X}$-ray diffraction and physisorption studies have been employed to confirm the templating effect of the surfactant. ${ }^{11,12,14}$ The diffusion of individual $\mathrm{CTA}^{+}$molecules inside zeolite crystals was confirmed by repeating the same surfactant-templating method with bulkier headed surfactants $\left(\mathrm{CTPA}^{+}\right)$, which was unable to generate any mesoporosity. ${ }^{12,15}$ Therefore, only small-headed surfactants (such as $\mathrm{CTA}^{+}$) that can diffuse through the micropores of the zeolite to reach the $\mathrm{SiO}^{-}$sites are suitable for the surfactant-templating method. $^{12,15}$

Received: August 24, 2021

Accepted: November 22, 2021

Published: November 29, 2021 
(a)

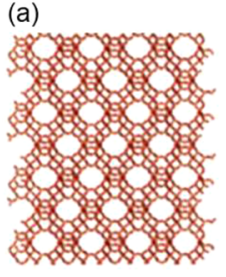

$\mathrm{NaY}$

(b)

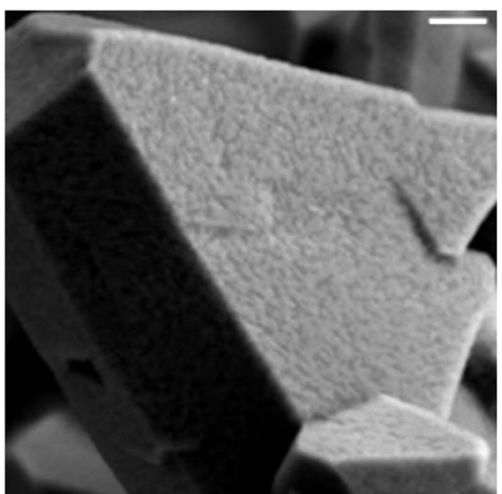

(c)

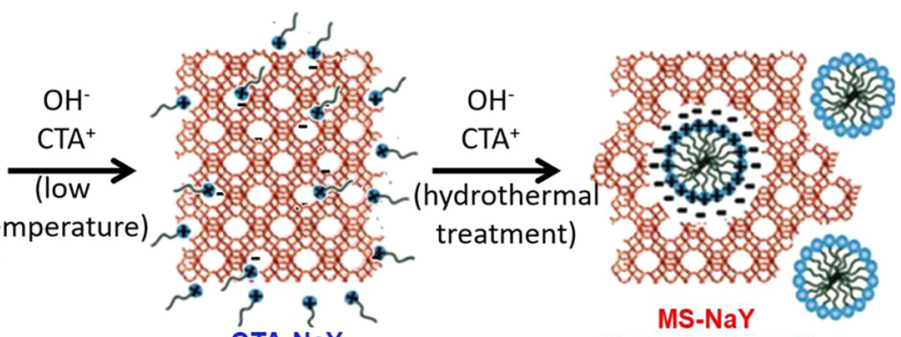

CTA-NaY

(d)
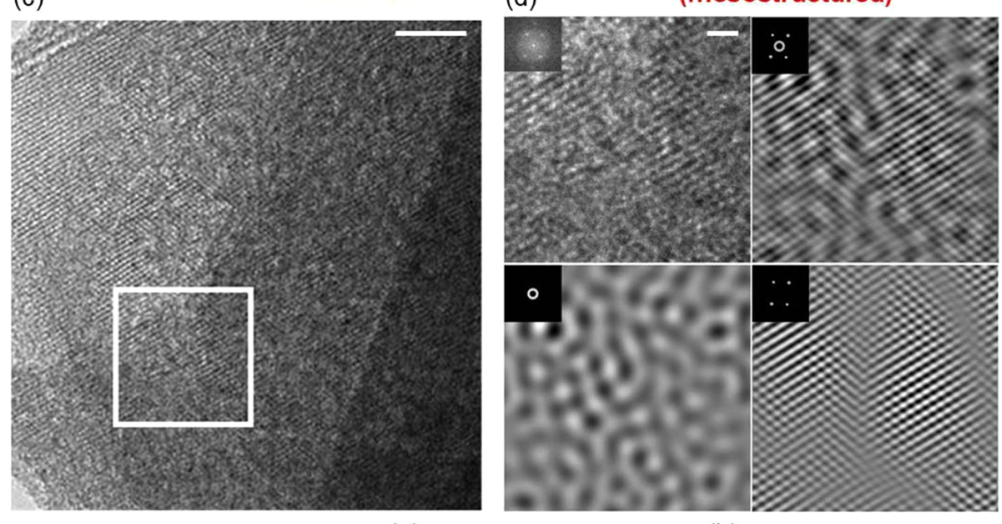

(g) 320

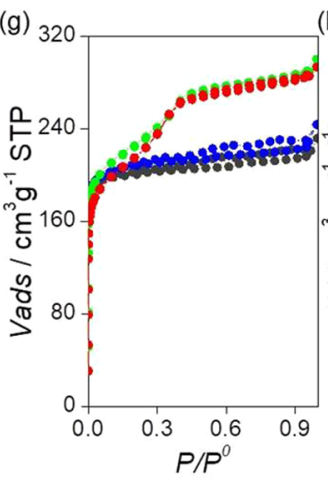

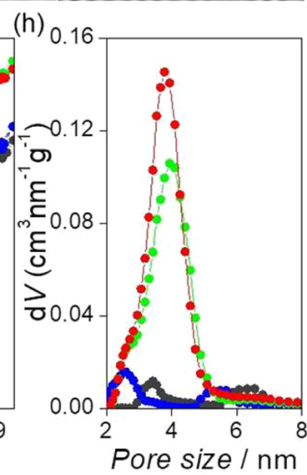

(e)

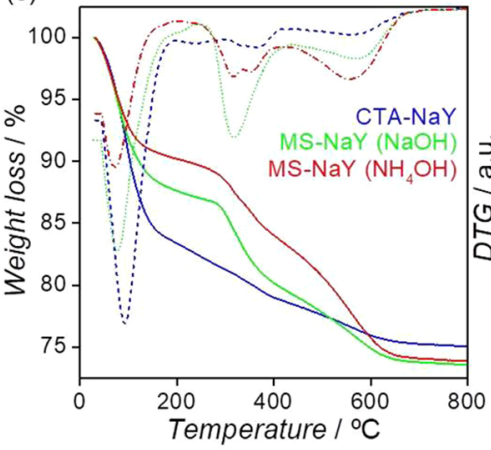

(f)

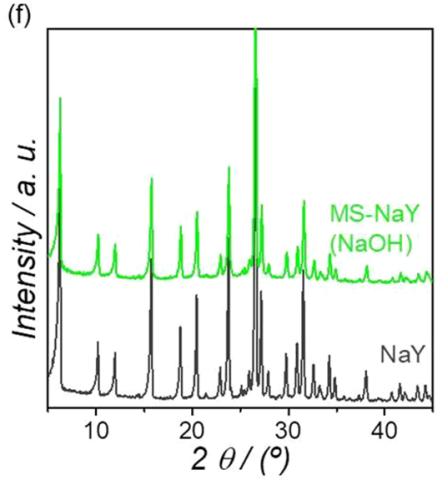

$P / P$

Figure 1. (A) Schematic representation of the surfactant-templating process in faujasite zeolite. (B) FE-SEM image of the surfactanttemplated zeolite in the presence of $\mathrm{NH}_{4} \mathrm{OH}$. Scale bar represents $200 \mathrm{~nm}$ in both images. (C) TEM micrograph of an ultramicrotomed slide of the sample MS-NaY $(\mathrm{NaOH})$. Scale bar corresponds to $20 \mathrm{~nm}$. The square marks the region for the fast Fourier transform (FFT) analysis. (D) Digital analysis of the TEM image. Top row: (left) Selected region for the analysis (FFT in the inset). Scale bar corresponds to $5 \mathrm{~nm}$. (right) Reconstruction of the micrograph showing both mesoporosity and crystallinity features obtained from both the spots and the halo of the FFT. Bottom row: (left) Reconstruction of the mesopore features obtained from the halo of the FFT. (right) Reconstruction of the crystalline structure from the spots of the FFT. (E) Thermogravimetric/difference thermal gravimetry (TG-DTG) measurements of zeolites before the hydrothermal treatment (blue) and after (red) the treatment with $\mathrm{NH}_{4} \mathrm{OH}$ at $150{ }^{\circ} \mathrm{C}$ and (green) the treatment with $\mathrm{NaOH}$ at 80 ${ }^{\circ} \mathrm{C}$. The TGA (solid line) is presented along with the DTG data (dashed line). (F) X-ray diffraction (XRD) patterns of the original NaY zeolite (gray) and the MS-NaY ( $\mathrm{NaOH})$. (G) $\mathrm{N}_{2}$ physisorption isotherms at $77 \mathrm{~K}$ for the original $\mathrm{NaY}$ (black), the pretreated NaY (blue), and the surfactant-templated zeolites with different bases, $\mathrm{NH}_{4} \mathrm{OH}$ (red) and $\mathrm{NaOH}$ (green), and ( $\mathrm{H}$ ) their corresponding pore size distribution.

Herein the use of Raman microspectroscopy allows us to go a step forward in the characterization of these surfactanttemplated mesoporous zeolites. Through spatially resolved molecular spectroscopy, we have been able to see and distinguish, for the first time, not only the entry of $\mathrm{CTA}^{+}$ into zeolites but, what is more relevant, also the formation of micelles inside the zeolites that underwent the reported procedure. The formation of micelles inside the zeolite crystals is the key for this method, which has been a great matter of debate since it was first reported. Raman scattering is wellsuited for the characterization of organic molecules and their organization. $^{16-19}$ The vibrational frequency and the relative intensity of the Raman modes shed light on the presence of functional groups in molecules and their local environment and organization. Through Raman microscopy, these insights can be spatially resolved in $3 \mathrm{D}$ on the submicrometer scale. Traditional, broadband spontaneous Raman microspectroscopy is particularly suited for resolving detailed molecular information from selected locations inside complex materials. ${ }^{17}$ The longer acquisition time per location, typically on the second scale, however, limits mapping large volumes. More advanced, coherent Raman spectroscopy, such as stimulated Raman scattering (SRS) microscopy, is ideally suited to trace specific vibrational signatures throughout samples. ${ }^{19}$ As such, the combination of broadband spontaneous Raman microspectroscopy with single-band SRS microscopy mapping allows one to investigate the molecular distribution and the local environment in complex materials on the submicron scale. Moreover, the analysis of individual particles permits one to assess the homogeneity of the final material, contrarily to the 
(a)

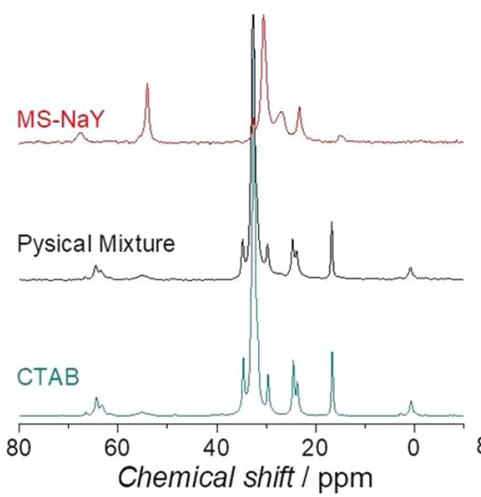

(b)

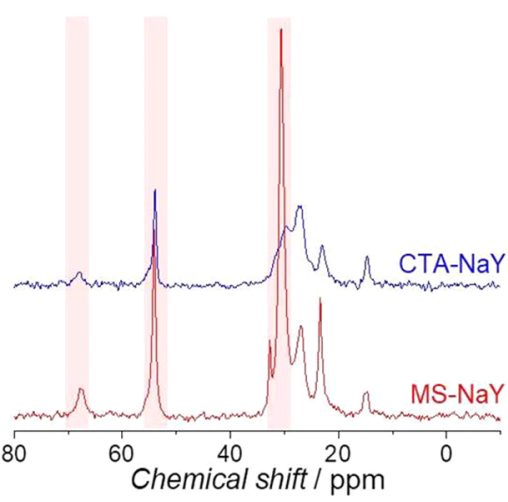

(c)
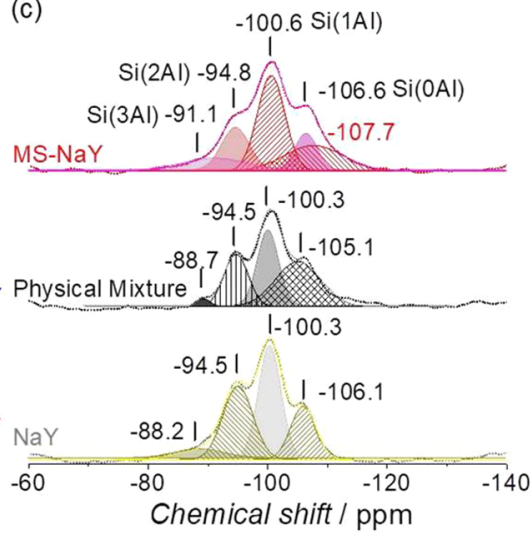

Figure 2. (A) Solid-state ${ }^{13} \mathrm{C}$ NMR spectra of the surfactant-templated zeolite (red), a physical mixture of NaY and CTAB (black), and CTAB (light blue). (B) Solid-state ${ }^{13} \mathrm{C}$ NMR of the surfactant-templated zeolite (red) and the CTA ${ }^{+}$-containing zeolite before the hydrothermal treatment (blue). (C) Solid-state ${ }^{29} \mathrm{Si}$ spectra of the surfactant-templated zeolite (red), the original NaY (gray), and a physical mixture of $\mathrm{NaY}$ and CTAB (black).
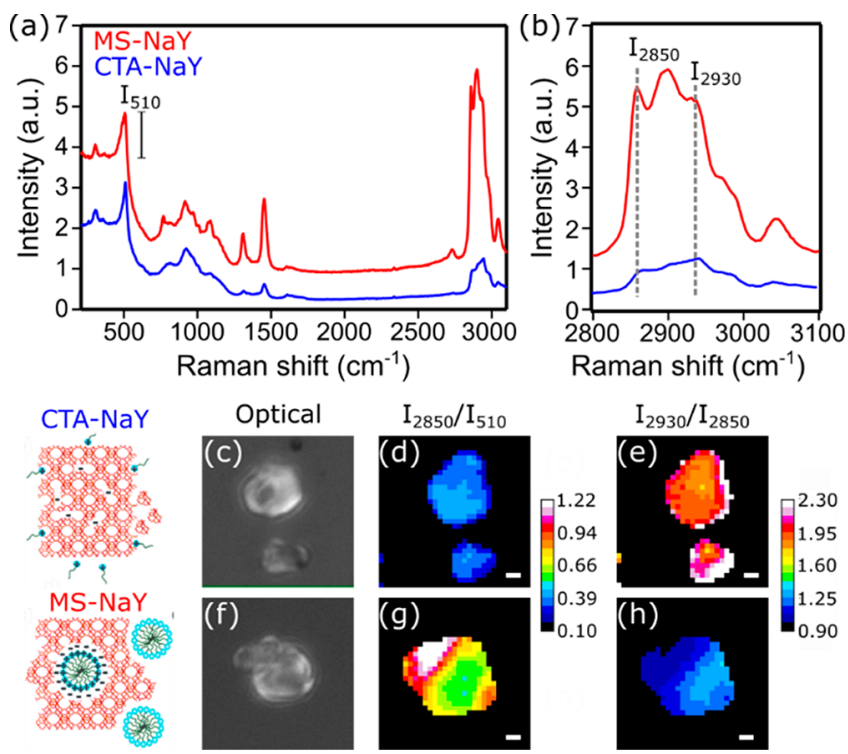

Raman shift $\left(\mathrm{cm}^{-1}\right)$

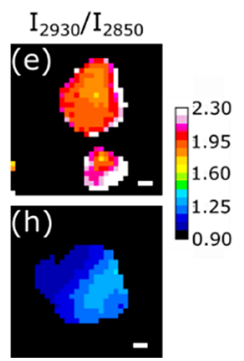

Figure 3. (a) Raman spectra of $\mathrm{CTA}^{+}$-loaded zeolite $\mathrm{Y}$ crystals before (blue) and after (red) hydrothermal treatment. (b) $\mathrm{CH}$ stretching vibrational signatures of both samples. (c,f) Optical images of representative zeolite $\mathrm{Y}$ crystals before and after hydrothermal treatment, respectively. (d,g) Maps of the Raman signal in the $\mathrm{CH}$-stretching region $\left(2850 \mathrm{~cm}^{-1}\right)$ normalized by the contribution of the zeolite framework $\left(510 \mathrm{~cm}^{-1}\right)$ of pretreated and hydrothermally treated crystals, respectively (scale bar: $1 \mu \mathrm{m}$ ). (e,h) Map of the $\rho_{2930 / 2850}$ ratio in pretreated and hydrothermally treated crystals, respectively (scale bar: $1 \mu \mathrm{m}$ ).

possible formation of two different phases (an amorphous mesoporous material and a crystalline microporous phase) that has been reported in the past. $^{20,21}$

Figure 1A shows the main steps involved in the surfactant templating of zeolites. Large $\mathrm{NaY}$ zeolite crystals were synthesized with an average size of $2000 \mathrm{~nm}$ (Figure 1B) so that they could be studied using optical microscopy; see the SI for details. The presence of a high $\mathrm{Al}$ content within the zeolite framework $(\mathrm{Si} / \mathrm{Al}=3.3)$ hinders the opening of the $\mathrm{Si}-\mathrm{O}-\mathrm{Al}$ bonds by the base (Figure S1). To overcome this limitation, a mild acid pretreatment was carried out to cleave some of the $\mathrm{Si}-\mathrm{O}-\mathrm{Al}$ bonds. ${ }^{12,22,23}$ Subsequently, and because of the large size of the particles, the acid-washed zeolite was stirred for $6 \mathrm{~h}$ in a neutral solution of surfactant to enhance the diffusion of $\mathrm{CTA}^{+}$molecules inside the crystals. These two pretreatments do not produce any mesoporosity, as shown in Figure $1 \mathrm{G}, \mathrm{H}$ (blue line), yet when this mixture was hydrothermally treated in the presence of a base (with either $\mathrm{NaOH}$ or $\mathrm{NH}_{4} \mathrm{OH}$; see the SI for details), a large amount of well-defined mesoporosity develops, as shown by their $\mathrm{N}_{2}$ isotherms at $77 \mathrm{~K}$ (Figure $1 \mathrm{G}$ ) and the field-emission-scanning electron microscopy (FESEM) and transmission electron microscopy (TEM) micrographs (Figure 1B-D; see Figures S2 and S3 for details of the digital analysis).

These highly mesoporous crystals maintain all of the X-ray diffraction peaks (Figure $1 \mathrm{~F}$ ) and the characteristic octahedral shape of the parent $\mathrm{NaY}$ (Figure $1 \mathrm{~B}$ and Figure S2). The amount of $\mathrm{CTA}^{+}$interacting with the zeolite framework was determined by thermogravimetric analysis (TGA). As previously reported, ${ }^{11,24}$ the fraction of surfactant that is responsible for the formation of mesoporosity corresponds to the amount of $\mathrm{CTA}^{+}$removed between 250 and $400{ }^{\circ} \mathrm{C}$. Figure 1E shows the TGA of (1) the zeolite after the pretreatments and before the hydrothermal process (CTA$\mathrm{NaY}$ ) and mesoporous zeolites after the hydrothermal treatment by using (2) $\mathrm{NaOH}$ as a base (MS-NaY $(\mathrm{NaOH})$ ) and (3) $\mathrm{NH}_{4} \mathrm{OH}$ as a base (MS-NaY $\left(\mathrm{NH}_{4} \mathrm{OH}\right)$ ). As expected, the amount of $\mathrm{CTA}^{+}$in the $250-400{ }^{\circ} \mathrm{C}$ range was higher in the hydrothermally treated sample, which is related to the formation of the micelles and, subsequently, of the mesoporosity. ${ }^{12,24}$

The micellization of the $\mathrm{CTA}^{+}$inside the zeolite and its subsequent effect on the zeolite structure were studied by solid-state ${ }^{13} \mathrm{C}$ and ${ }^{29} \mathrm{Si} \mathrm{NMR}$; see Figure 2. The ${ }^{13} \mathrm{C} \mathrm{NMR}$ spectrum of the $\mathrm{CTA}^{+}$-containing zeolite after the hydrothermal treatment is shown in Figure 2A (red). For comparison purposes, the spectra of two control samples are also included, namely, the solid crystalline CTAB (light blue) and a physical mixture of $\mathrm{NaY}$ and CTAB (black). The physical mixture was prepared using the same NaY/CTAB ratio determined in the surfactant-templated zeolite by TGA. The chemical shifts of the ${ }^{13} \mathrm{C}$ NMR spectrum of CTAB (Figure 2B, light blue) closely match those reported elsewhere. ${ }^{25}$ The complete assignment according to its structural formula can be found in Figure S4. The physical mixture of the zeolite and the surfactant shows very similar chemical shifts for 

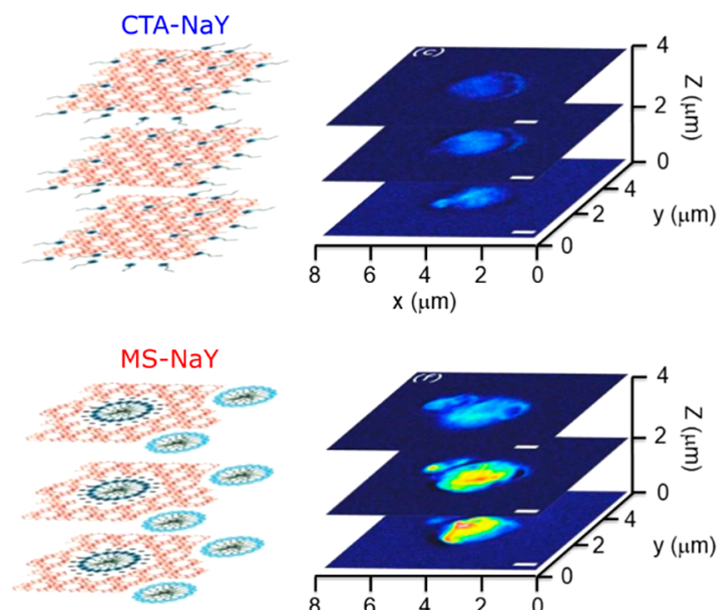

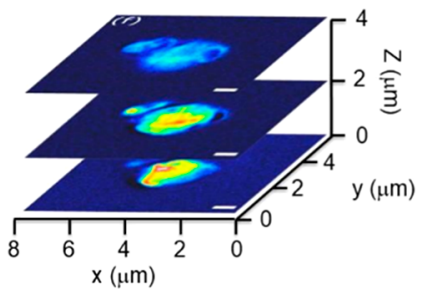

$\mathrm{Z}=0 \mu \mathrm{m}$

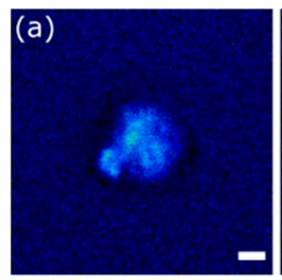

$\mathrm{Z}=2 \mu \mathrm{m}$
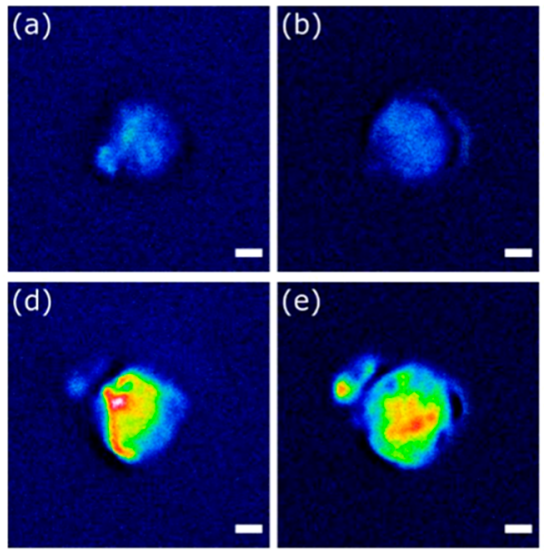

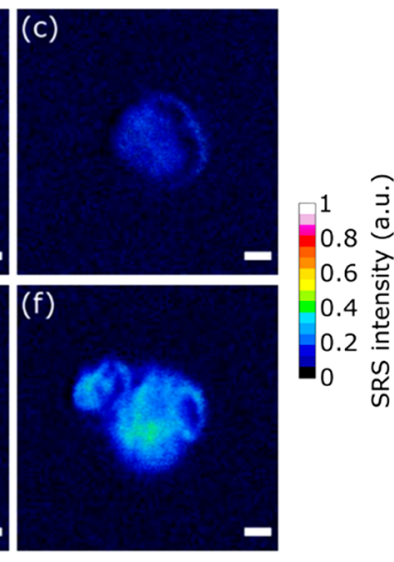

Figure 4. False-color SRS images acquired at $2850 \mathrm{~cm}^{-1}$ of zeolite $Y$ crystals $(a-c)$ after pretreatment and (d-f) after hydrothermal treatment at different focal planes. The SRS images were recorded at $(\mathrm{a}, \mathrm{d}) 0,(\mathrm{~b}, \mathrm{e}) 2$, and $(\mathrm{c}, \mathrm{f}) 4 \mu \mathrm{m}$ from the crystal-glass interface $(\mathrm{scale}$ bars: $1 \mu \mathrm{m})$.

the CTAB molecules, indicating a similar chemical environment. $^{26}$ However, after the hydrothermal treatment, the surfactant molecules in the surfactant-templated zeolite produce broader resonance peaks, which are shifted compared with the solid CTAB. This behavior suggests a more fluid-like environment similar to a micellar solution of the surfactant. Similar findings have also been reported for the mesoporous MCM-41 silica, indicating the presence of micelles in the zeolite crystals. $^{27-29}$ The sharp resonance at $54 \mathrm{ppm}$ is characteristic of micelled (or trapped) surfactant in the zeolite structure, $^{28,30}$ whereas the broadening and decrease in the intensity of the peak at ca. $67 \mathrm{ppm}$ is due to the interaction of the surfactant heads with the polar environment inside the zeolitic structure, which changes the chemical environment of the CTAB. To study the micellization process, we analyzed the CTA-containing zeolite before the hydrothermal treatment (see Figure 2B). The obtained spectrum shows chemical shifts similar to those of the mesostructured zeolite, although the resonances are much broader and with lower intensity, even with the disappearance of some signals. This observation points out the lack of densely packed molecules, suggesting more isolated molecules within the zeolite framework. ${ }^{30}$ Solidstate ${ }^{29} \mathrm{Si}$ NMR spectra were carried out to gain new insights into the changes in the zeolite framework caused by the surfactant-templating treatment (Figure 2C). The original zeolite shows the characteristic peaks associated with the different structural units of the aluminosilicate framework ( $\mathrm{Si}(0 \mathrm{Al}), \mathrm{Si}(1 \mathrm{Al}), \mathrm{Si}(2 \mathrm{Al}), \mathrm{Si}(3 \mathrm{Al}))^{31}$ (see Figure $2 \mathrm{C}$ ), which are very similar to those of the physical mixture. However, in the hydrothermally treated sample, a new broad peak at a higher field appears, whereas the $\mathrm{Si}(0 \mathrm{Al})$ band shifts to a lower field, which can be attributed to the formation of different types of structural defects during the surfactant templating process, $^{32}$ which is related to the formation of the mesoporous system.

These bulk-scale data suggest that the surfactant-templated mesostructuration process starts with the adsorption of isolated $\mathrm{CTA}^{+}$cations inside the zeolite crystals during the pretreatment, which, upon hydrothermal treatment, restructure into micelles, leading to the formation of well-defined mesoporosity.
To gain further insights into the distribution and local organization of $\mathrm{CTA}^{+}$cations, we characterized the CTABloaded samples at the single zeolite crystal level using spontaneous Raman microspectroscopy. First, the uptake of $\mathrm{CTA}^{+}$molecules was studied using the $\mathrm{CH}$-stretching vibrations of the $\mathrm{CTA}^{+}$cation $\left(2800-3100 \mathrm{~cm}^{-1}\right)$ and those in relation to the zeolite framework signatures (300-600 $\mathrm{cm}^{-1}$ ) (Figure 3a). The more intense signals in the $\mathrm{CH}$ region after hydrothermal treatment suggest a higher $\mathrm{CTA}^{+}$loading in these crystals, in agreement with the TGA data; to compare the Raman signals of $\mathrm{CTA}^{+}$in crystals before and after hydrothermal treatment, we normalized the spectra with respect to the intensity of the band associated with the four-membered rings of the zeolite, centered at ca. $510 \mathrm{~cm}^{-1} .33$

Whereas these Raman spectra were collected from a location at the center of individual zeolite particles, the presence of $\mathrm{CTA}^{+}$throughout the whole zeolite was confirmed by spatially mapping the $\mathrm{CH}$-stretching signal at different focal planes with SRS microscopy (Figure 4). Indeed, the SRS signal associated with the $\mathrm{CTA}^{+}$cations is observed at different focal planes in both pretreated and hydrothermally treated zeolite crystals. However, the SRS intensity in pretreated zeolite crystals is much lower, in agreement with the spontaneous Raman spectroscopy data (Figure 3).

The $\mathrm{CH}$ region, while complex in nature due to the overlapping $\mathrm{CH}_{2}$ and $\mathrm{CH}_{3}$ symmetric and asymmetric stretching modes, contains valuable information on the organization of $\mathrm{CTA}^{+}$cations inside the zeolite particles. Previous studies of $\mathrm{CTAB}$ in various solutions have linked the relative Raman signal intensity at $2930 \mathrm{~cm}^{-1}\left(I_{2930}\right)$, that is the symmetric $\mathrm{CH}_{3}$ stretching, to that at $2850 \mathrm{~cm}^{-1}\left(I_{2850}\right)$, that is the symmetric $\mathrm{CH}_{2}$ stretching mode, to the local polarity surrounding the $\mathrm{CTA}^{+}$alkyl chain environment. ${ }^{34,35} \mathrm{~A}$ decreasing local polarity results in a decreased $\rho_{2930 / 2850}=$ $I_{2930} / I_{2850}$. For the $\mathrm{CTA}^{+}$-treated zeolite $\mathrm{Y}$, the $\rho_{2930 / 2850}$ in crystals decreases from 1.4 before hydrothermal treatment to 0.9 after hydrothermal treatment (Figure 3a,b). This shift reveals a drastically less polar environment due to micelle formation. Note that in previous studies, micellization resulted in a similar decreasing $\rho_{2930 / 2850}$. In this system, the drop in the polarity is rationalized by the transition from mostly isolated 
$\mathrm{CTA}^{+}$cations in direct contact with the polar zeolite environment to closely packed $\mathrm{CTA}^{+}$micelles with an apolar local environment. These results are in line with the observation from ${ }^{13} \mathrm{C}$ NMR. The location of $\mathrm{CTA}^{+}$cations in pretreated (Figure 3c) and hydrothermally treated (Figure 3f) zeolite $\mathrm{Y}$ crystals can be mapped by spatially resolving the Raman signature of $\mathrm{CH}$-stretching modes, normalized by the signal of the zeolite framework. The hydrothermal treatment of $\mathrm{CTA}^{+}$-loaded zeolite $\mathrm{Y}$ crystals leads to a significant yet inhomogeneous increase in the $\mathrm{CTA}^{+}$loading (Figure $3 \mathrm{~d}, \mathrm{~g}$ ). The heterogeneities in the surfactant molecule loading are ascribed to the nonuniform distribution of defects in the zeolite crystals. Likewise, the distribution of the ratio $\rho_{2930 / 2850}$ can be assessed in individual crystals (Figure $3 \mathrm{e}, \mathrm{h}$ ). The local polarity of $\mathrm{CTA}^{+}$cations is slightly higher in the outer shell of pretreated crystals (Figure $3 \mathrm{e}$ ). In a similar way as the $\mathrm{CTA}^{+}$ distribution, the formation of micelles indicated by a decrease in the ratio $\rho_{2930 / 2850}$ occurs in a nonuniform way in the hydrothermally treated crystals. Lower values of $\rho_{2930 / 2850}$ are observed in intracrystalline regions with higher $\mathrm{CTA}^{+}$loading.

To confirm that $\mathrm{CTA}^{+}$micelle formation is not featurespecific for the large zeolite crystals used in this study, we followed the same procedure with the commercially available FAU zeolite (CBV100) typically used for mesostructuration. ${ }^{12}$ In a similar way, the mesostructuration of these (smaller) zeolites induced during the hydrothermal treatment also leads to a decrease in the intensity ratio of the bands centered at 2930 and $2850 \mathrm{~cm}^{-1}$; see Figure S5.

In summary, by combining ${ }^{13} \mathrm{C}$ NMR and Raman microspectroscopy, we have been able to unequivocally prove that during the hydrothermal treatment steps, the individual $\mathrm{CTA}^{+}$ molecules first penetrate inside the zeolite crystals and then self-assemble to form micelles in the interior of the zeolites. Moreover, and thanks to Raman microspectroscopy, we have been able to spatially resolve in $3 \mathrm{D}$ the presence of these micelles throughout the zeolite crystals, which confirms our previous observations of the presence of well-defined mesoporosity homogeneously distributed inside the zeolites.

\section{ASSOCIATED CONTENT}

\section{SI Supporting Information}

The Supporting Information is available free of charge at https://pubs.acs.org/doi/10.1021/acsmaterialslett.1c00514.

Experimental details regarding the synthesis and characterization of the materials and supplementary figures (showing the energy-dispersive X-ray analysis of the parent zeolite, the FE-SEM micrograph of the parent $\mathrm{NaY}$ zeolite, the TEM and Gatam digital analyses of the surfactant-templated zeolite, the solid-state spectrum of CTAB with the corresponding assignation, and the Raman study of the commercially available FAU zeolite) (PDF)

\section{AUTHOR INFORMATION}

\section{Corresponding Authors}

Maarten B. J. Roeffaers - Centre for Membrane Separations, Adsorption, Catalysis and Spectroscopy for Sustainable Solutions (cMACS) Department of Microbial and Molecular Systems, KULeuven, 3001 Leuven, Belgium; (1) orcid.org/ 0000-0001-6582-6514; Email: maarten.roeffaers@ kuleuven.be
Javier García-Martínez - Laboratorio de Nanotecnología Molecular, Departamento de Química Inorgánica Universidad de Alicante, Alicante E-03690, Spain; ○ orcid.org/0000-0002-7089-4973; Email: j.garcia@ua.es

\section{Authors}

Guillaume Fleury - Centre for Membrane Separations, Adsorption, Catalysis and Spectroscopy for Sustainable Solutions (cMACS) Department of Microbial and Molecular Systems, KULeuven, 3001 Leuven, Belgium; ㅇoㄷ․org/ 0000-0001-9480-3952

Monica J. Mendoza-Castro - Laboratorio de Nanotecnología Molecular, Departamento de Química Inorgánica Universidad de Alicante, Alicante E-03690, Spain

Noemi Linares - Laboratorio de Nanotecnología Molecular, Departamento de Química Inorgánica Universidad de Alicante, Alicante E-03690, Spain; 이이이.org/0000-00019376-2984

Complete contact information is available at:

https://pubs.acs.org/10.1021/acsmaterialslett.1c00514

\section{Notes}

The authors declare no competing financial interest.

\section{ACKNOWLEDGMENTS}

We thank the European Commission for funding through the H2020-MSCA-RISE-2019 program (ref. ZEOBIOCHEM 872102) and the Spanish MINECO and AEI/FEDER, UE through the project ref RTI2018-099504-B-C21. N.L. acknowledges the University of Alicante support (UATALENTO1705). M.J.M.-C. thanks the Generalitat Valenciana for a Ph.D. fellowship (GRISOLIAP/2020/165). M.B.J.R. acknowledges financial support from the FWO for the investment in microscopy (AKUL/15/15 - G0H0816N and G0H6316N ZW15_09) and financial support from the KU Leuven Research Fund (C14/19/079).

\section{REFERENCES}

(1) Mesoporous Zeolites: Preparation, Characterization and Applications; García-Martínez, J., Li, K., Eds.; Wiley-VCH Verlag GmbH \& Co. KGaA: Weinheim, Germany, 2015.

(2) Chen, L. H.; Sun, M. H.; Wang, Z.; Yang, W.; Xie, Z.; Su, B. L. Hierarchically Structured Zeolites: From Design to Application. Chem. Rev. 2020, 120, 11194-11294.

(3) Kerstens, D.; Smeyers, B.; Van Waeyenberg, J.; Zhang, Q.; Yu, J.; Sels, B. F. State of the Art and Perspectives of Hierarchical Zeolites: Practical Overview of Synthesis Methods and Use in Catalysis. Adv. Mater. 2020, 32, 2004690.

(4) Hartmann, M.; Machoke, A. G.; Schwieger, W. Catalytic Test Reactions for the Evaluation of Hierarchical Zeolites. Chem. Soc. Rev. 2016, 45, 3313-3330.

(5) Bai, R.; Song, Y.; Li, Y.; Yu, J. Creating Hierarchical Pores in Zeolite Catalysts. Trends Chem. 2019, 1, 601-611.

(6) Sun, Q.; Xie, Z.; Yu, J. The State-of-the-Art Synthetic Strategies for SAPO-34 Zeolite Catalysts in Methanol-to-Olefin Conversion. Natl. Sci. Rev. 2018, 5, 542-558.

(7) Čejka, J.; Millini, R.; Opanasenko, M.; Serrano, D. P.; Roth, W. J. Advances and Challenges in Zeolite Synthesis and Catalysis. Catal. Today 2020, 345, 2-13.

(8) Masoumifard, N.; Guillet-Nicolas, R.; Kleitz, F. Synthesis of Engineered Zeolitic Materials: From Classical Zeolites to Hierarchical Core-Shell Materials. Adv. Mater. 2018, 30, 1704439.

(9) Sachse, A.; García-Martínez, J. Surfactant-Templating of Zeolites: From Design to Application. Chem. Mater. 2017, 29, $3827-3853$. 
(10) Mendoza-Castro, M. J.; Serrano, E.; Linares, N.; GarcíaMartínez, J. Surfactant-Templated Zeolites: From Thermodynamics to Direct Observation. Adv. Mater. Interfaces 2021, 8, 2001388.

(11) Linares, N.; Jardim, E. O.; Sachse, A.; Serrano, E.; GarcíaMartínez, J. The Energetics of Surfactant-Templating of Zeolites. Angew. Chem., Int. Ed. 2018, 57, 8724-8728.

(12) Sachse, A.; Grau-Atienza, A.; Jardim, E. O.; Linares, N.; Thommes, M.; García-Martínez, J. Development of Intracrystalline Mesoporosity in Zeolites through Surfactant-Templating. Cryst. Growth Des. 2017, 17, 4289-4305.

(13) Linares, N.; De Oliveira Jardim, E.; Sharma, G.; Serrano, E.; Navrotsky, A.; García-Martínez, J. Thermochemistry of SurfactantTemplating of USY Zeolite. Chem. - Eur. J. 2019, 25, 10045-10048. (14) Linares, N.; Sachse, A.; Serrano, E.; Grau-Atienza, A.; De Oliveira Jardim, E.; Silvestre-Albero, J.; Cordeiro, M. A. L. M. A. L.; Fauth, F.; Beobide, G.; Castillo, O.; et al. In Situ Time-Resolved Observation of the Development of Intracrystalline Mesoporosity in USY Zeolite. Chem. Mater. 2016, 28, 8971-8979.

(15) De Oliveira Jardim, E.; Serrano, E.; Martínez, J. C. J. C.; Linares, N.; García-Martínez, J. Consecutive Surfactant-Templating Opens up New Possibilities for Hierarchical Zeolites. Cryst. Growth Des. 2020, 20, 515-520.

(16) Hess, C. New Advances in Using Raman Spectroscopy for the Characterization of Catalysts and Catalytic Reactions. Chem. Soc. Rev. 2021, 50, 3519-3564.

(17) Fleury, G.; Roeffaers, M. B. J. Correlating Acid Site Distribution and Catalytic Activity in Dealuminated Mordenite at the SingleParticle Level. ACS Catal. 2020, 10, 14801-14809.

(18) Fleury, G.; Roeffaers, M. B. J. Resolving the Acid Site Distribution in Zn-Exchanged ZSM-5 with Stimulated Raman Scattering Microscopy. Catalysts 2020, 10, 1331.

(19) Fleury, G.; Steele, J. A.; Gerber, I. C.; Jolibois, F.; Puech, P.; Muraoka, K.; Keoh, S. H.; Chaikittisilp, W.; Okubo, T.; Roeffaers, M. B. J. Resolving the Framework Position of Organic StructureDirecting Agents in Hierarchical Zeolites via Polarized Stimulated Raman Scattering. J. Phys. Chem. Lett. 2018, 9, 1778-1782.

(20) Ivanova, I. I.; Knyazeva, E. E. Micro-Mesoporous Materials Obtained by Zeolite Recrystallization: Synthesis, Characterization and Catalytic Applications. Chem. Soc. Rev. 2013, 42, 3671-3688.

(21) Verboekend, D.; Milina, M.; Mitchell, S.; Pérez-Ramírez, J. Hierarchical Zeolites by Desilication: Occurrence and Catalytic Impact of Recrystallization and Restructuring. Cryst. Growth Des. 2013, 13, 5025-5035.

(22) García-Martínez, J.; Johnson, M.; Valla, J.; Li, K.; Ying, J. Y. Mesostructured Zeolite Y-High Hydrothermal Stability and Superior FCC Catalytic Performance. Catal. Sci. Technol. 2012, 2, 987.

(23) García-Martínez, J.; Li, K.; Krishnaiah, G. A Mesostructured Y Zeolite as a Superior FCC Catalyst - from Lab to Refinery. Chem. Commun. 2012, 48, 11841

(24) Peng, C.; Liu, Z.; Yonezawa, Y.; Linares, N.; Yanaba, Y.; Trujillo, C. A. C. A.; Okubo, T.; Matsumoto, T.; García-Martínez, J.; Wakihara, T. Testing the Limits of Zeolite Structural Flexibility: Ultrafast Introduction of Mesoporosity in Zeolites. J. Mater. Chem. A 2020, 8, 735-742.

(25) Lavine, B. K.; Cooper, W. T.; He, Y.; Hendayana, S.; Han, J. H.; Tetreault, J. Solid-State 13C NMR Studies of Ionic Surfactants Adsorbed on C-18 and C-8 Silicas: Implications for Micellar Liquid Chromatography. J. Colloid Interface Sci. 1994, 165, 497-504.

(26) Kumar, R.; Chen, H. T.; Escoto, J. L. V.; Lin, V. S. Y.; Pruski, M. Template Removal and Thermal Stability of Organically Functionalized Mesoporous Silica Nanoparticles. Chem. Mater. 2006, 18, 4319-4327.

(27) Beck, J. S.; Vartuli, J. C.; Roth, W. J.; Leonowicz, M. E.; Kresge, C. T.; Schmitt, K. D.; Chu, C. T. W.; Olson, D. H.; Sheppard, E. W.; McCullen, S. B.; et al. A New Family of Mesoporous Molecular Sieves Prepared with Liquid Crystal Templates. J. Am. Chem. Soc. 1992, 114, 10834-10843.

(28) Beck, J. S.; Vartuli, J. C.; Kennedy, G. J.; Kresge, C. T.; Roth, W. J.; Schramm, S. E. Molecular Or Supramolecular Templating: Defining The Role of Surfactant Chemistry In the Formation of M41S and Zeolitic Molecular Sieves. Stud. Surf. Sci. Catal. 1995, 98, 15-16. (29) Khalil, U.; Liu, Z.; Peng, C.; Hikichi, N.; Wakihara, T.; GarcíaMartínez, J.; Okubo, T.; Bhattacharya, S. Ultrafast SurfactantTemplating of *BEA Zeolite: An Efficient Catalyst for the Cracking of Polyethylene Pyrolysis Vapours. Chem. Eng. J. 2021, 412, 128566.

(30) Xu, D.; Feng, J.; Che, S. An Insight into the Role of the Surfactant CTAB in the Formation of Microporous Molecular Sieves. Dalt. Trans. 2014, 43, 3612-3617.

(31) Lippmaa, E.; Mági, M.; Samoson, A.; Tarmak, M.; Engelhardt, G. Investigation of the Structure of Zeolites by Solid-State HighResolution 29Si NMR Spectroscopy. J. Am. Chem. Soc. 1981, 103, $4992-4996$.

(32) Ivanova, I. I.; Kasyanov, I. A.; Maerle, A. A.; Zaikovskii, V. I. Mechanistic Study of Zeolites Recrystallization into Micro-Mesoporous Materials. Microporous Mesoporous Mater. 2014, 189, 163172.

(33) Dutta, P. K.; Twu, J. Influence of Framework Silicon/ Aluminum Ratio on the Raman Spectra of Faujasitic Zeolites. J. Phys. Chem. 1991, 95, 2498-2501.

(34) da Costa, A. M. A.; Geraldes, C. F. G. C.; Teixeira-Dias, J. J. C. Micellar Aggregation of CTAB in Water and Chloroform Solutionsa Study by Laser Raman Spectroscopy. J. Colloid Interface Sci. 1982, $86,254-259$.

(35) Li, P.; Xiong, G.; Liu, L.; Wang, L. Investigation on the Effect of Zeolite Precursor on the Formation Process of MCM-41 Containing Zeolite Y Building Units. Spectrochim. Acta, Part A 2013, 107, 218226.

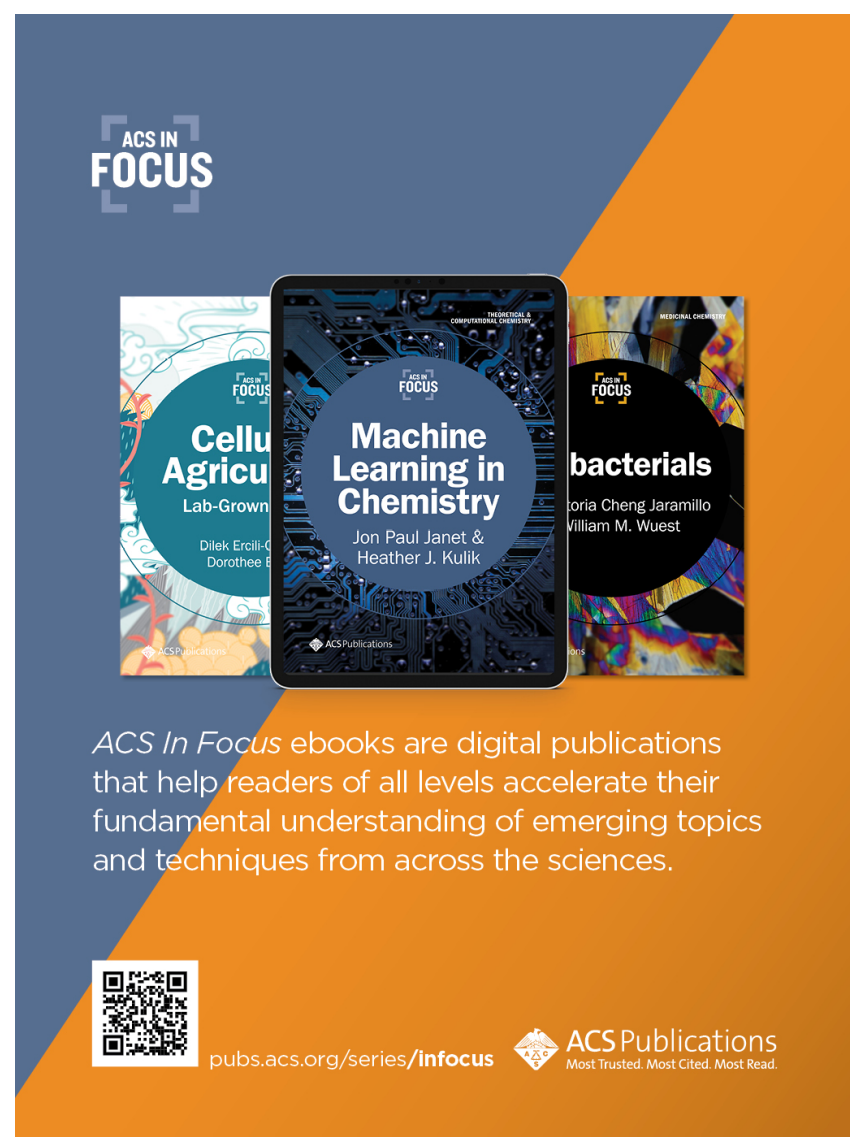

